\title{
La gestión de los cementerios históricos: La muerte como disputa
}

\section{The historic cemeteries management: Death as a dispute}

\author{
Arturo Ruiz Taboada \\ Centro de Estudios Internacionales. Fundación Ortega Marañón \\ taboada@arrakis.es
}

Recibido: 24-12-2013

Aceptado: 12-02-2014

\begin{abstract}
RESUMEN
El objeto de este trabajo es analizar la gestión actual de los cementerios históricos. Para ello, el artículo se centra en la reciente polémica surgida a raíz de la excavación arqueológica de un cementerio judio en Toledo. La exhumación de las tumbas supuso la ingerencia internacional en una gestión que únicamente recae sobre el estado español y la comunidad autónoma competente. El caso de Toledo es uno más de los acontecidos en otras ciudades patrimoniales de España y del resto de Europa e ilustra la polémica sobre el tratamiento de este tipo de restos y las consecuencias que pueden derivarse de su gestión.
\end{abstract}

Palabras clave: Gestión de patrimonio, cementerios históricos, judios ultra ortodoxos.

\begin{abstract}
The aim of this paper is to analyze the current management of historical cemeteries. The article focuses on the recent controversy caused by the archaeological excavation of a Jewish cemetery in Toledo. The exhumation of tombs saw the involvement of the international community in an issue that solely concerns the Spanish state and the particular local authorities to which the remains belong. This case study is one amongst many instances occurring in other Spanish cities as well as in the rest of Europe, and it illustrates the controversy surrounding the treatment of this type of remains.
\end{abstract}

KEY WORDs: Heritage management, historical cemeteries, ultra-Orthodox Jews. 


\section{Introducción}

El artículo sintetiza mediante una serie de casos prácticos la evolución que ha sufrido la gestión de restos humanos históricos durante las últimas décadas, tomando como referencia la reciente polémica con motivo de la excavación de un cementerio judío en Toledo ${ }^{1}$. En esta gestión, disciplinas como la arqueología y la antropología se han visto en la necesidad de revisar sus planteamientos académicos clásicos, y adaptarlos a las crecientes reivindicaciones provenientes de movimientos sociales, políticos y religiosos (Hodder 2003: 44). Estos planteamientos no sólo afectan a cuestiones de carácter científico, en los que antropólogos y arqueólogos han tenido que ponerse de acuerdo a la hora de desarrollar sus estudios sobre ello (Baffi y Berón 2000), sino de carácter social relacionado con la recuperación de la memoria histórica perdida a raíz de conflictos de distinta naturaleza (Walsh-Haney y Lieberman 2005; Salmona y Sigal 2011; Cosmai et al. 2013). En este sentido, no es lo mismo analizar restos humanos de comunidades extinguidas en la actualidad, que aquellos que aún conservan vínculos culturales y genéticos con el presente. Así, el artículo inicia este debate centrándose en algunos acontecimientos de finales del siglo XX como las leyes de la NAGPRA o la gestión de cementerios como el Commons de Manhattan, precedentes de la gestión actual de los restos humanos, caracterizada siempre por la polémica y las legítimas reivindicaciones de los grupos de población afectados. Para ello, se toma como modelo la reciente controversia surgida en torno a la excavación del cementerio judío de Toledo y su relación con otros casos repartidos por toda Espa-

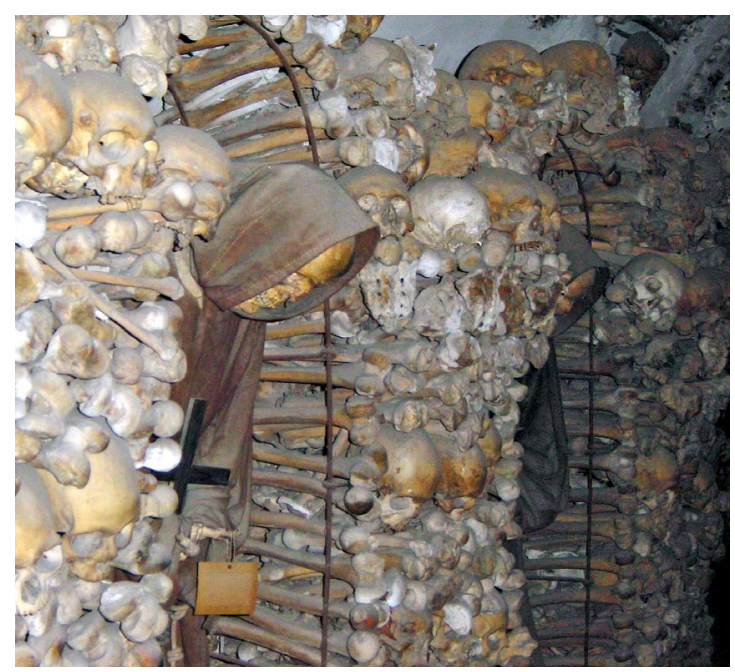

Figura 1.- Cripta de Santa Maria della Concezione dei Cappuccini (Roma). ña. Como veremos, este tipo de conflictos, demanda el diseño de protocolos específicos de actuación ante cada situación particular (Aranda y Del Papa 2009: 90).

En la actualidad, el tratamiento de restos humanos varía según los casos. Estos pueden sufrir una sobreprotección por parte de la sociedad que los genera o, por el contrario, la total indiferencia. $\mathrm{Su}$ consideración va a estar siempre ligada al contexto social en el que se encuentran. Cualquier sociedad que analicemos tiene sus propias normas sobre el tratamiento de estos restos y, dentro de ellas, pueden darse combinaciones infinitas dependiendo de la intención que se persiga con ello. Por ejemplo, los osarios son buen ejemplo de la diversificación que puede darse en las prácticas funerarias, cuyo tratamiento, simbolismo y estética, en muchos casos, puede resultar hasta obscena para según qué grupos (Fig. 1).

La muerte es el reflejo de nuestra existencia y constituye uno de los acontecimientos más importantes dentro de una comunidad (Ruiz Taboada 2013). Desde la primera evidencia arqueológica de ritual funerario en el paleolítico, hemos asistido a infinidad de formas de concebir la muerte dependiendo de la época, cultura o religión asociadas. Además de una despedida, el ritual se apoya en la muerte para dar a conocer las características de la sociedad a la que pertenece el difunto. En muchos casos, el acto de enterrar o, por el contrario, de no enterrar, se concibe como símbolo de poder, con la misión de transmitir un mensaje tanto a la propia comunidad como a las comunidades vecinas. Las arquitecturas funerarias se convierten así en grandes carteles publicitarios de la sociedad que las genera. Las formas de representar este poder van desde las grandes pirámides que caracterizan el mundo funerario de muchas culturas antiguas, a tumbas más sencillas, aunque con la misma carga simbólica. Estos monumentos pierden con el tiempo la función originaria para la que fueron diseñados. En el caso de las pirámides de Egipto, la civilización que las concibió ya no existe, en su lugar, la sociedad egipcia actual, mayoritariamente musulmana, ha pasado de considerarlas como parte de su identidad como pueblo, a meros generadores de riqueza gracias al turismo. La expectación y el respeto vivido a finales del siglo XIX cuando August Mariette traslada a El Cairo por el Nilo las momias de los faraones procedentes del Valle de los Reyes, ya forma parte del recuerdo. En ese momento, el acontecimiento reunió a la población junto a las orillas del río para dar un último adiós a sus antepasados. 


\section{Precisiones en torno al tratamiento de los restos humanos}

Los pueblos que se consideran herederos de su pasado tienden a exigir soluciones jurídicas para la salvaguarda de su patrimonio. Los casos seleccionados son una pequeña muestra que ilustra la gestión del patrimonio funerario en litigio. En todos ellos, el marco jurídico es diferente y, únicamente se ciñe al caso concreto, en un intento de solventar el problema puntual, más que de crear un modelo válido permanente para su gestión. La consecuencia es que cualquier norma, siempre se quedará pequeña para resolver un conflicto tipo que puede reproducirse en cualquier momento y en cualquier comunidad del mundo.

La sociedad indígena norteamericana fue pionera en tomar conciencia sobre la importancia de salvaguardar su pasado. En la década de los 70 del siglo XX, la demanda presentada por María Pearson dio inicio a una corriente que ha permitido preservar cualquier resto humano perteneciente a las sociedades nativas de los Estados Unidos de América. La Ley de Protección y Repatriación de las Tumbas de Americanos Nativos (NAGPRA) marca un antes y un después en la preservación de este tipo de restos. Esta ley de1990, agrupa y complementa la legislación anterior en esta materia (Bruning 2006; Rodríguez López 2009: 60). No obstante, la aplicación real de esta norma ha resultado ser cuanto menos complicada. Como señala Silberman (2012: 238) el caso del hombre de Kennewick (Washington) ilustra la cautela que debe imperar en la gestión de este tipo de restos, en la que confluyen intereses científicos, culturales y étnicos, al tiempo que duda sobre la utilidad de diseñar leyes generales para cuestiones de identidad. Su descubrimiento casual y su posterior estudio antropológico puso en guardia a los nativos americanos que reclamaron para si los huesos, de acuerdo a la política establecida por la NAGPRA. Se inició así un largo litigio para determinar su titularidad, finalizando al comprobar que el individuo no era nativo americano, sino homo sapiens. Al no poder demostrar que este hombre fuera el antecesor de las tribus indígenas locales, el proceso se desestimó.

La mera reivindicación de la herencia material, cultural o genética de algunos pueblos no implica su legitimidad. Tenemos casos en los que el componente social del problema se instrumentaliza para justificar determinados intereses políticos y económicos. En este sentido, la historia simplemente es la que es y cualquier intento de cambiarla o reescribirla restará legitimidad a quienes lo promuevan. No se puede negar la conquista musulmana de

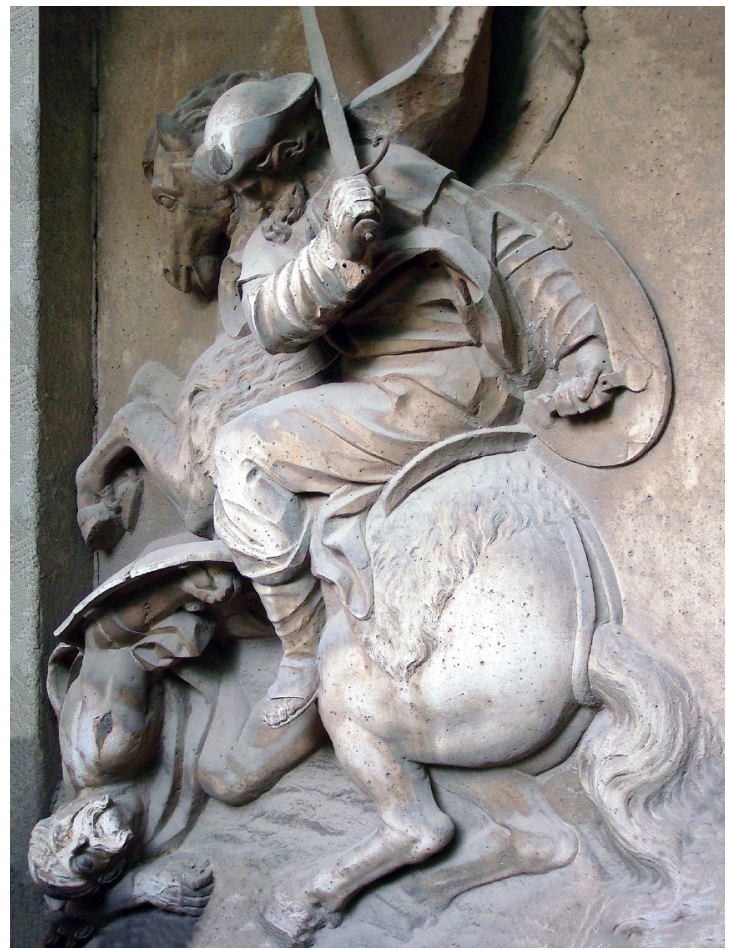

Figura 2.- Representación de Santiago "Matamoros". Portada del convento de Santa Fe (Toledo).

al Andalus (VIII), aunque tampoco el fenómeno de la reconquista (XI-XV). Ambos sucesos históricos han generado símbolos y momentos que, sacados de contexto hoy en día, podrían resultar ofensivos para las partes implicadas (Fig. 2).

Un ejemplo de uso de la memoria de minorías étnicas foráneas para el interés general se encuentra en la excavación del cementerio histórico del Commons (African Burial Ground National Monument) en Nueva York, que albergaba los restos de afroamericanos, esclavos que entre $1600 \mathrm{y}$ 1796 contribuyeron a crear la ciudad. En esta época, entre el diez y el veinte por ciento de los habitantes eran de procedencia africana. El cementerio se encontraba localizado a las afueras y se estima que, en origen pudo albergar entre 10.000 y 20.000 enterramientos. En la Nueva York colonial, a los africanos no se les estaba permitido enterrarse en las iglesias, estuvieran convertidos al cristianismo o no (Blakey 1998: 53). Durante muchos años los africanos y sus descendientes han luchado por encontrar su sitio en Estados Unidos. La importancia de esa etnia en el desarrollo del imperio americano ha sido siempre la base de muchos estudios históricos, en los que la norma era la de rechazar su papel en su desarrollo. Este debate ha implicado siempre a líderes sociales y religiosos de la co- 
munidad, así como a numerosos investigadores. El descubrimiento de este cementerio durante las obras de construcción de un edificio federal en el Bajo Manhattan en 1991, ha permitido cambiar muchos de los estereotipos culturales referidos a la comunidad afro americana (Thomas 2002: 144).

Lo que hace a este caso diferente a otros, es que en la gestión de la excavación se tuvo en cuenta por parte de las autoridades competentes la contratación de un prestigioso antropólogo físico afroamericano, Michael Blakey, profesor del Departamento de Antropología y Sociología de la Universidad de Howard. Aunque polémico, este gesto sirvió tanto para aplacar a la comunidad étnica local, recelosa de la manipulación de los restos de sus antepasados, como para posibilitar la realización de estudios antropológicos. Una vez analizados, fueron devueltos a la comunidad y re-inhumados en el mismo sitio, que fue declarado Monumento Nacional en el año 2006 (Silberman 2012: 238). Esta declaración no sólo se hizo de cara a los afro americanos, sino para el resto de los estadounidenses, en reconocimiento a su papel en la construcción de la Nación. Un pequeño museo de sitio recuerda el sufrimiento de esta minoría étnica. En él se puede aprender sobre sus ritos y costumbres, pero también de las calamidades que sufrieron por parte de la sociedad blanca dominante.

El ejemplo contrario lo encontramos en el cementerio judío de Beit Shearim (Israel), caso que ilustra el concepto de negación de evidencias materiales en un intento de justificación de los orígenes históricos de un Estado. Esta necrópolis del siglo III después de Cristo, se encuentra localizada en la Baja Galilea, compuesta de una serie de catacumbas en las cuales se han encontrado más de cien sarcófagos. Es un centro que en su momento acogió judíos provenientes de diferentes regiones del Oriente Medio. El yacimiento es único, pues contiene muchos de los símbolos que atestiguan que se trata de una necrópolis judía, cosa que es muy difícil de encontrar en cementerios medievales europeos de la misma religión. Entre las piezas halladas destaca una memorá. El yacimiento se convierte en centro de atención internacional tras la destrucción de esta memorá por parte de judíos ultra ortodoxos. Como veremos más adelante, estos grupos son uno de los oponentes radicales del Estado judío obsesionados con preservar la tierra sagrada de los antiguos cementerios judíos. Ellos parten de la premisa de que no puede haber Estado de Israel hasta que no llegue el Mesías y, como este símbolo representa al Estado de Israel, está aludiendo a un Estado inexistente (Silvan 2012: 31).

Los cementerios representan la sociedad que los concibe y, por tanto, secularmente han sido moneda de cambio a lo largo de la historia. En el Toledo de la Edad Media los Reyes Católicos vendieron las lápidas del cementerio judío en un intento de minimizar la memoria de su presencia en la ciudad (Ruiz Taboada 2011: 292). Esta damnatio memoriae ha sido habitual en todas las civilizaciones antiguas. En la actualidad, los cementerios siguen siendo el centro de las reivindicaciones políticas y sociales, no importa la religión a la que se pertenezca. Prueba de ello es la reciente polémica sobre la destrucción parcial del cementerio medieval islámico de Mamilla en Jerusalén occidental, por parte de los israelíes, para construir el Museo de la Tolerancia y de la Dignidad Humana, dependiente del Centro Simon Wiesenthal, con sede en Los Ángeles (New York Times, 13 Agosto de 2010), o el saqueo y destrucción de mausoleos cristianos en Mali por islamistas radicales (New York Times, 2 de Julio de 2012).

En este contexto, la arqueología ha jugado un papel fundamental en la gestión de estos cementerios, al servir de instrumento para justificar la intervención en ellos o criticarla (Stultz 2012). La excavación de estos lugares, por tanto, debe atender a criterios de conservación y divulgación del patrimonio, sin que concurran intereses políticos o religiosos de ningún tipo. En los casos en los que no sea posible su conservación, se debe asegurar la pervivencia de su memoria mediante la divulgación del hallazgo.

De igual forma, en los últimos años hemos asistido a un incremento de solicitudes de repatriación de restos humanos conservados en museos. El hombre de Bañolas es uno de los primeros ejemplos que ilustra los problemas de gestión de este tipo de restos, junto con la cabeza de maorí del museo de Rouen, devuelta a Nueva Zelanda en el 2011 o la Venus de Hotentote, una mujer africana fallecida en París en 1815, que fue expuesta en diferentes museos franceses hasta su devolución a Sudáfrica en 2004. En el caso español, este bosquimano que fue desenterrado en 1830 , disecado y conducido a Francia por naturalistas franceses, acabó finalmente en un museo de esta localizad catalana. En 1916 el negro llegó a Bañolas como parte de las colecciones que Francesc Dardes donó a la ciudad y que constituyeron el museo que lleva su nombre. En 1992, la polémica fue iniciada por el médico Alfonso Arcelín quien solicitó "dignificar al hombre disecado, pidiendo que sea devuelto a su lugar de origen probablemente Botsuana para ser enterrado o incinerado tras una ceremonia de desagravio". La resistencia de los vecinos de Bañolas, en principio de escaso alcance local, tomó características de conflicto diplomático entre España y los países 
de la Organización para la Unidad Africana. A ello se sumó la Asociación de Museólogos de Cataluña que consideraron que el bosquimano tenía «gran valor patrimonial y museístico» por lo cual debería conservarse. Finalmente la intervención de la UNESCO, aconsejando la inhumación o el traslado del bosquimano, finalizó la polémica con su incineración (Endere 2000: 10).

La gestión de restos humanos históricos en España no difiere de la de otros países y se enmarca generalmente en el mundo académico, aunque en algunas ocasiones pueden verse involucrados agentes sociales ajenos a estos ámbitos. De una parte, en el campo meramente científico, se fomenta el conocimiento de los rituales de enterramiento desde la prehistoria hasta nuestros días. De otra, el interés por estos restos va más allá de la academia e implica a sectores de la sociedad preocupados por la gestión que pueda hacerse de los restos de sus antepasados. En los últimos años, se ha complicado el fondo de esta gestión puesto que se ha pasado de tramitar problemas puntuales como el hombre de Bañolas, a cuestiones más generales como el caso de los cementerios de origen judío o la recuperación y dignificación de aquellos que murieron durante la última contienda civil.

En este último supuesto, la aprobación de la Ley de Memoria Histórica en el año 2007 (Ley $52 / 2007$, de 26 de diciembre), ha propiciado la creación de una nueva ortodoxia en el tratamiento de restos humanos, que tiene por objeto la exhumación y dignificación de aquellas personas anónimas que fueron enterradas en fosas comunes con motivo de esta guerra. En los últimos años, la opinión pública española ha estado dominada por intensos debates basados en la memoria histórica de aquellos que murieron en el bando republicano durante la Guerra Civil (1936-1939) y padecieron la posterior dictadura de Franco (1939-1975).

Después de años de silencio en interés de consolidar nuestro sistema democrático, hoy en día no faltan proyectos y estudios encaminados a recuperar y dignificar la memoria del bando perdedor de la contienda. No obstante, la indudable legitimidad de esta demanda, puede quedar en un segundo plano debido a lo reciente de los acontecimientos. Pese a los casi 80 años transcurridos, aún planea la idea de que para algunos, esta Ley puede ser vista como un intento de ganar sobre el papel una guerra que se perdió hace muchos años. El hecho de que muchas de las personas que participaron en la contienda en uno u otro bando ya hayan fallecido, complica cualquier reivindicación. La elección del momento adecuado, como en otros casos similares, siempre es motivo de disputa puesto que para unos este tipo de reparaciones llega tarde, mien- tras que, para otros, demasiado pronto. En el año 2000 se crea la asociación para la recuperación de la Memoria Histórica, con el objetivo de obtener apoyo público para investigar los abusos ocurridos durante la época de Franco. Siendo una de las pioneras en España, gran parte de su trabajo se ha centrado en identificar y exhumar fosas comunes de la Guerra Civil, con la noble intención de devolver a sus familiares los restos enterrados. La primera exhumación tuvo lugar en el año 2000, recuperando los restos humanos de 13 personas fusiladas por los partidarios de Franco en 1936. Desde ese momento se han producido exhumaciones similares por toda la geografía española, en donde la cifra de fosas comunes estimada por esta asociación ronda las 600 .

Las fosas comunes son la materialización de actos de extrema violencia y clave para identificar dinámicas del terror social y político de las sociedades que las generan. La identificación y estudio de este tipo de tumbas ha sido siempre fuente de conflictos, ansiedad y división en las sociedades que se enfrentan a ellas (Ferrándiz 2006: 7; 2009). A lo largo del siglo XX se generaliza la búsqueda de las verdades históricas mediante la exhumación de las fosas comunes derivadas de conflictos políticos y sociales por todo el globo. La documentación de estos restos se ha convertido en icono para identificar y definir el sufrimiento humano. Especialmente para mostrar la violencia contra la población civil. Así, ya forman parte de nuestra retina las imágenes de esqueletos y cráneos apilados de los crímenes de Pol Pot en Camboya, las matanzas de tutsis por hutus en Ruanda, mostradas en memoriales repartidos por todo el país como el de la iglesia Kibuye, o las reivindicaciones para conocer su historia inmediata en Argentina, Guatemala y, ahora, España (Renshaw 2011: 10).

Las razones de estas exhumaciones hay que buscarlas en una compleja maraña de intereses de todo tipo, aunque todos ellos se sirven de cuestiones sentimentales para su legitimación en según qué foro (Fig. 3). En estos casos, se debe ser muy cuidadoso con la instrumentalización que se hace de ellas, puesto que una reivindicación legítima, se puede convertir en una manipulación ideológica del hecho luctuoso.

En este sentido, son los hijos y, en muchos casos, nietos de los del bando perdedor los que están promoviendo esta recuperación de la memoria. Pero no es lo mismo una reivindicación sentimental desde la neutralidad que otorga el paso del tiempo a otra que, en muchos aspectos, puede ser considerada como oportunista por la implicación política de alguna de estas asociaciones, en donde el concurso ideológico eclipsa claramente cual- 


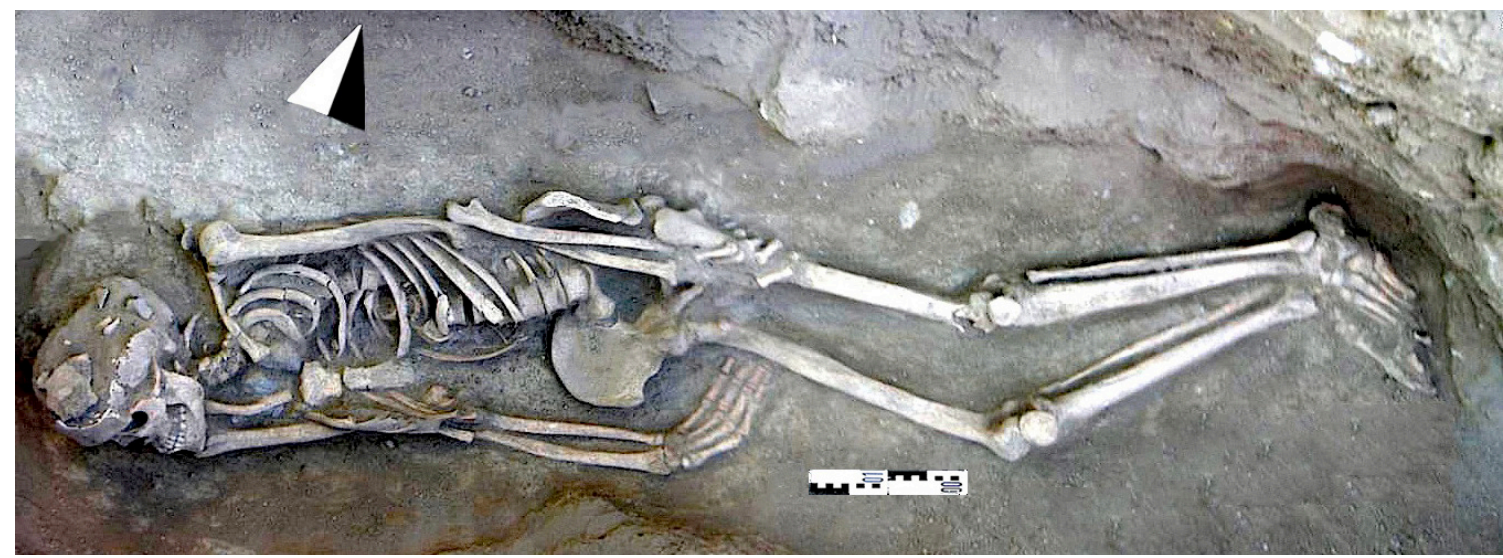

Figura 3.- Individuo perteneciente al bando franquista asociado con la saca de la puerta del Cambrón y fuente del Salobre (22 de Agosto 1936). La fosa común a la que pertenece se encuentra en el número 3 de la calle de los Canónigos (Toledo).

quier intención reparadora o sentimental sobre las familias que sufrieron la pérdida.

Como hemos visto en otros casos analizados en este artículo, la ideología tiende a corromper cualquier buena intención. Se debe, por tanto, dar prioridad a la simple restitución de la memoria de aquellos olvidados en las cunetas de las carreteras españolas o las fosas comunes de los cementerios. Estos actos serán completamente legítimos cuando se prime la restitución moral y sentimental de los afectados frente al beneficio político y, como en el caso del Commons, su fin sea únicamente conciliador. Por tanto, se sigue echando de menos una gestión coherente y sensible, diseñada desde un Estado, que aglutine y reconcilie a todas las partes implicadas, cuyo único fin debe ser el trabajo por y para la sociedad que gobierna y la búsqueda de su bienestar.

A continuación se analiza un caso que ilustra la segunda circunstancia que concurre en el tratamiento actual de restos humanos de naturaleza histórica en España. La gestión actual de los cementerios medievales en Toledo pone de manifiesto tanto el vacío legal que existe en este campo, pese a las actuales leyes de patrimonio a nivel nacional y regional existentes, como los problemas étnicos y religiosos que pueden surgir con este tipo de actuaciones.

\section{La gestión de los cementerios medievales de Toledo: El caso judío}

Algunas sociedades se consideran propietarias de sus cementerios al dar por sentado que no existe solución de continuidad entre ellos y sus antepasados (Silberman 2012: 234). Una de las comunidades más activas en la preservación de sus enterramientos es la judía. En los últimos años hemos asistido en España a un incremento de peticiones de re inhumación de restos pertenecientes a esta etnia aparecidos en contextos arqueológicos. El primer caso lo encontramos en Valencia, con el descubrimiento en 1996 de una necrópolis judía del siglo XIV en Romagosa. El Ayuntamiento de Valencia y la Consejería de Cultura, a instancias de la Federación de Comunidades Israelitas de España, autoriza el traslado de los cuerpos a un cementerio de Barcelona sin ser previamente analizados por los arqueólogos que efectuaron la excavación. Los mismos problemas se han ido reproduciendo desde entonces, a lo largo de la geografía española. Los casos del cementerio judío de Toledo y Ávila son los más recientes, junto con la inauguración y puesta en valor del cementerio judío de Lucena en septiembre de 2013 tras una larga negociación.

Toledo se caracteriza por la gran cantidad de cementerios localizados extramuros (Fig. 4). Las excavaciones arqueológicas en el marco de la legislación vigente (Ley de Patrimonio de Castilla La Mancha, 4/13), han evidenciado la necesidad de crear un plan de intervención integral que salvaguarde este tipo de restos. La gestión de estas excavaciones ha puesto de manifiesto la total desprotección que tienen los cementerios históricos de la ciudad, al no contemplar los proyectos arquitectónicos de actuación sobre ellos ni su conservación ni su contextualización en el conjunto urbano. En Toledo resulta habitual la práctica de dejar de excavar una tumba o hacerlo parcialmente, porque se encuentra fuera del área a intervenir. Hasta que no se cambie esta tendencia, poco o nada se podrá hacer para su salvaguarda. 


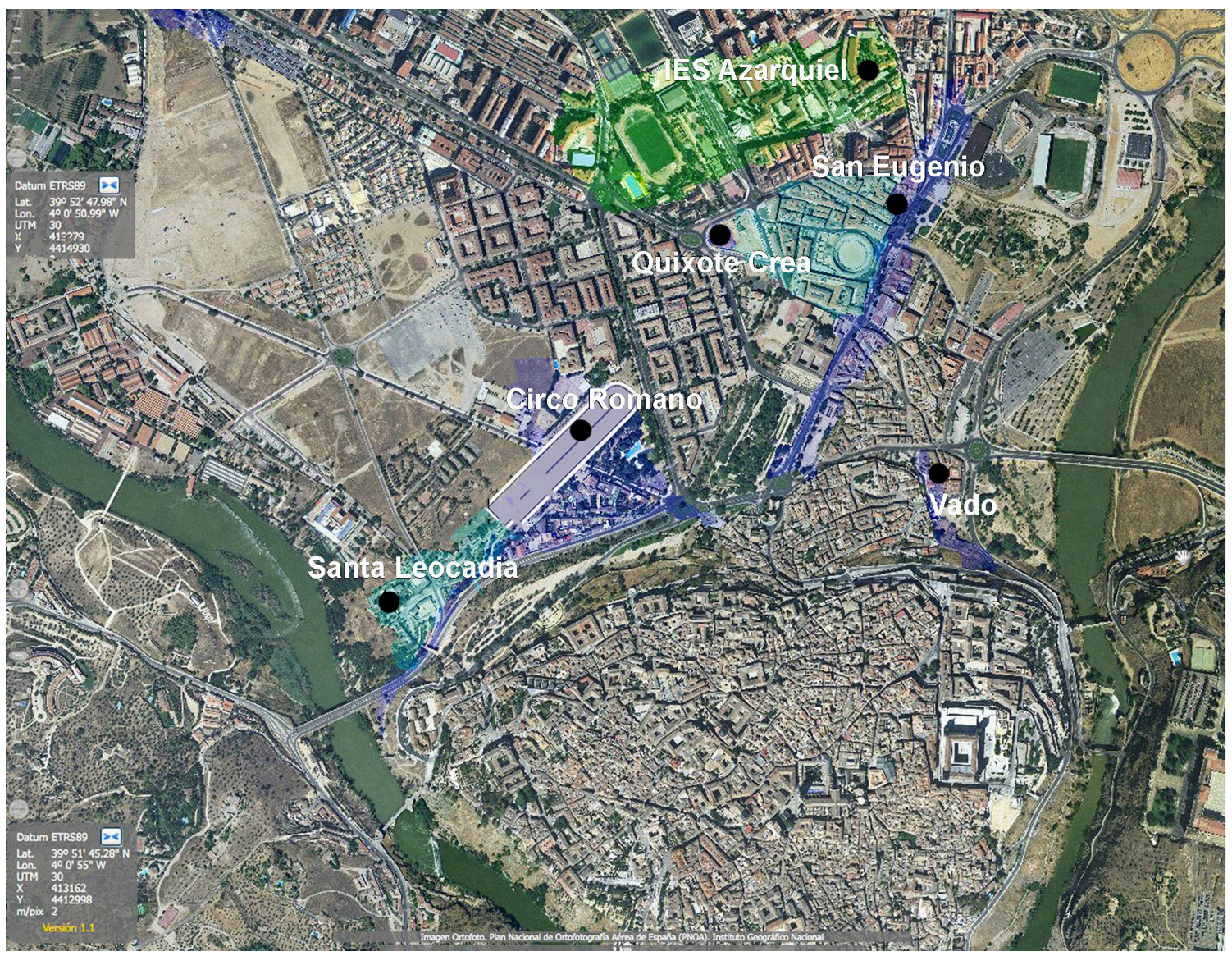

Figura 4.- Plano de situación del entorno cementerial medieval de Toledo (Instituto Geográfico Nacional, PNOA).

En el año 2009 se dio el primer aviso sobre la necesidad de tomar en serio este patrimonio tras los problemas políticos y religiosos derivados de la excavación en uno de los sectores centrales del antiguo cementerio judío de Toledo, en el actual IES Azarquiel. Esta intervención saltó a las páginas internacionales poniendo en serios apuros la independencia de las administraciones locales encargadas de su gestión. Poco tiempo después, otro caso también salpicaba las páginas de la prensa local y nacional con la destrucción parcial del cementerio medieval de San Lázaro, consecuencia de la construcción del complejo cultural Quixote Crea (Barrio Aldea y otros 2011), obra promovida por el Ayuntamiento de Toledo. En este caso, no confluían cuestiones ideológicas, étnicas o religiosas como en Azarquiel, sino meramente administrativas, puesto que los intereses políticos eran los que se anteponían a la necesidad de conservar y dar a conocer los restos descubiertos. El resultado fue la destrucción de 194 tumbas cuando, paradójicamente, ya se llevaban excavadas 1400. La falta de una política cultural clara propició su destrucción.
Las tumbas destruidas pertenecen al entorno del cementerio de la ermita de San Eugenio y están datadas entre los siglos XII y XV. Sólo cuando la noticia llega a la prensa local el 18 de enero de 2011, se produce una reacción desde la Administración Pública, obligando a reparar el daño causado a la empresa responsable, mediante el estudio antropológico del $10 \%$ de los huesos exhumadas. En la actualidad ninguna medida compensatoria se ha tomado, en espera de las resoluciones judiciales aún pendientes, sentando un peligroso precedente de cara a la gestión del patrimonio histórico de la ciudad, ya que se está creando un agravio comparativo entre los criterios seguidos para la obra privada y la obra pública, independientemente del daño patrimonial causado (Ruiz Taboada 2012).

Pero un año antes la administración local y regional se había tenido que enfrentar a un caso similar, aunque en esta ocasión con un trasfondo exclusivamente religioso. La aparición de una reseña en la prensa local, puso en guardia a la asociación Asra Kadisha, de ámbito internacional, en contra de la profanación de cementerios judíos. En sep- 


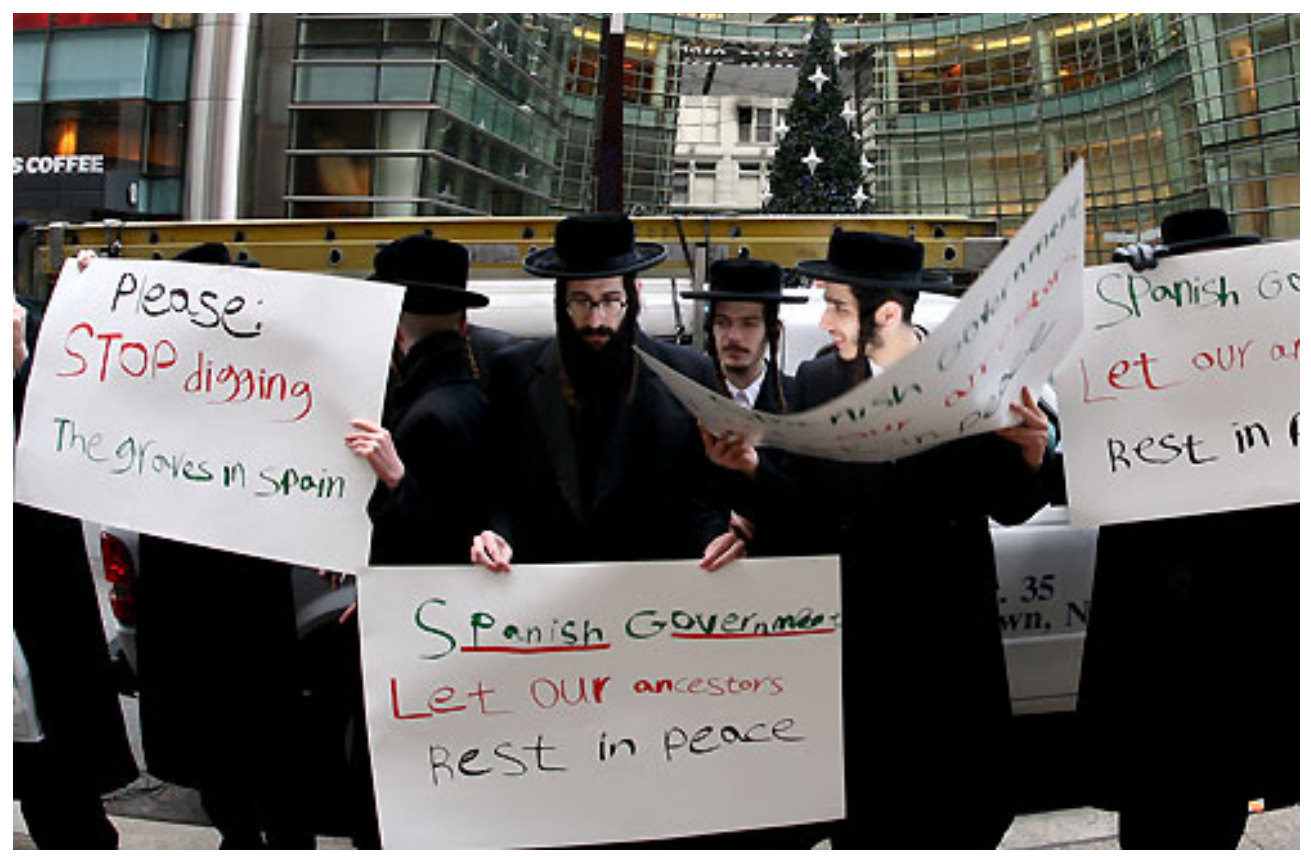

Figura 5.- Manifestación en contra de la excavación del IES Azarquiel y de la mediación de la Federación de Comunidades Judías de España, frente al consulado de España en Nueva York (30 de noviembre de 2008), según el ShalomNewYork.com.

tiembre de 2008, el diario la Tribuna de Toledo publicaba un pequeño artículo en el que se indicaba como anécdota que los alumnos del IES Azarquiel de Toledo iban a iniciar sus clases en presencia de nuevos compañeros «los restos de un cementerio judío medieval encontrado durante la construcción de seis nuevas aulas». Lo que en un principio se trataba de una noticia cotidiana para Toledo, al ser este tipo de intervenciones habituales en cualquier obra que afecte al subsuelo arqueológico de la ciudad, derivó en cuestión de días en un conflicto internacional (Ruiz Taboada 2013).

El argumento que esgrimía este grupo era que, por encima de los restos materiales contenidos en los museos, estos lugares guardaban la esencia de las comunidades de antaño y eran de su propiedad. La protesta internacional fue orquestada por el Congreso Central Rabínico (CRC) de Estados Unidos y Canadá, en el que uno de sus actos más mediáticos fue la manifestación y vigilia en noviembre de 2008, frente al Consulado de España en Nueva York, conjuntamente con los de Canadá e Israel. Una vigilia nocturna también tuvo lugar tras la valla de la excavación, aunque el acto más multitudinario tuvo lugar en mayo de 2009 en el Hotel Marriott de Brooklyn, en el que cientos de judíos ultra ortodoxos pidieron el respeto por las tumbas del cementerio de Toledo (Fig. 5).

A pesar de que las formas empleadas no fueron de las más correctas, al grupo liderado por el rabino Kalmanowitz, no le faltaba razón en cuanto a que la sociedad actual debe preservar las tumbas de sus antepasados. Este argumento, no obstante, debe ser también válido a la hora de aplicarlo a todas las religiones que habitaron Toledo y el resto de ciudades europeas en los que existen este tipo de restos, aunque siempre en el marco de las legislaciones vigentes en materia de patrimonio de cada país.

Después de cuatro paralizaciones, las excavaciones del IES Azarquiel finalizaron en enero de 2009. Dichas paralizaciones fueron consecuencia de la presión de Asra Kadisha, vía Departamento de Estado de Estados Unidos, sobre los Ministerios de Justicia y Exteriores del entonces Gobierno de España, y sobre la Junta de Comunidades de Castilla La Mancha, responsable de la gestión de este tipo de intervenciones. La mediación de la Federación de Comunidades Judías de España, junto con la conferencia de Rabinos Europeos (CER) y el Comité para la Preservación de Cementerios Judíos de Europa (CPJCE) permitió trabajar para dar una solución al conflicto surgido. Los trabajos se reanudaron tras la firma de un protocolo de actuación de naturaleza administrativa entre la Federación de Comunidades Judías y la Junta de Comunidades, el 18 de Noviembre de 2008. En dicho protocolo se reconocían los cementerios ju- 
díos como lugares de culto. El protocolo se había aplicado con anterioridad en Valencia y El Frago (Zaragoza), y había sido el instrumento de gestión para los casos de Lucena (Córdoba), Tárraga (Lérida) y Montjuic (Barcelona). Para el caso de Toledo, el objeto era la gestión de la exhumación de los restos humanos de necrópolis halladas en yacimientos arqueológicos de Castilla La Mancha. Este protocolo fue rubricado por la Consejera de Cultura, Turismo y Artesanía del momento y el presidente de la Federación de Comunidades Judías. Pese a su firma, la sensación hasta finalizar por completo la excavación era que podría haber sido paralizada en cualquier momento.

El protocolo de actuación, todavía en vigor aunque sin aplicación práctica, recoge en su punto segundo la obligatoriedad de comunicar a la federación cualquier hallazgo de restos de enterramientos judíos. Entre tanto, se deben conservar los cuerpos de forma individual hasta que se produzca el re-enterramiento bajo la dirección de un rabino autorizado por dicha federación. El lugar de esta re-inhumación debe ser, bien el mismo, o en el cementerio judío más próximo, siempre bajo supervisión rabínica. De igual forma, debido al gran valor histórico de estos restos, se propone señalizar con una lápida conmemorativa el lugar donde se encontraba este cementerio, al tiempo que se debe favorecer la designación del lugar como de interés histórico local.

Finalizada la excavación en enero, se inicia una carrera a contrarreloj por re-enterrar los restos exhumados. Entre el 13 y 16 de enero se habilita una fosa en un pinar cercano en la que se pretenden depositar los restos hallados, financiada por la Junta de Comunidades de Castilla La Mancha. Esta idea no convence a las autoridades rabínicas, puesto que la fosa se encontraba descontextualizada del cementerio. De forma paralela se propone a la Delegación de Educación, promotora de las obras, una reunión con Santos Benbunam, arquitecto de la Federación, y la dirección facultativa de las obras del colegio, encabezada por Federico Dietl Sagüés junto con el arqueólogo director de la excavación. En la reunión se sugiere el diseño en el sector afectado del cementerio, de una cimentación aérea con pilares distribuidos para no dañar la fosa de ninguna tumba. La opción se descarta por compleja y descabellada, dado que su financiación, diseño y ejecución correría a cargo de la Consejería de Educación. Finalmente se opta por el re-enterramiento en el propio colegio.

El 18 de junio las distintas partes acceden a reinhumar los restos a escasos metros del lugar donde fueron hallados, bajo supervisión rabínica. Para evitar destruir tumbas antiguas en la superficie se- leccionada, el rabino que dirigía estos trabajos no tuvo mas remedio que recurrir al arqueólogo director de las obras, para que le indicara la profundidad a la que aparecían los enterramientos. Los restos se depositaron individualmente en una estructura de rejilla a base de ladrillo. Una placa conmemora el lugar, como se recoge en el manifiesto antes descrito. En ella se puede leer en hebreo y castellano "ten compasión de todas las almas de las personas sepultadas aquí, el Rey Supremo con su infinita misericordia las proteja y queden apegadas a la vida eterna, descansen en paz, y diremos amen" (Fig. 6).

Según se publicó en la prensa local y nacional, la inhumación se realizó con respeto a la Halajá y fue supervisada por rabinos del Comité para la Preservación de Cementerios Judíos de Europa (CPJCE), en ella intervinieron el presidente del Consejo Superior Rabínico de España, el presidente de la FCJE, el presidente de la Hebrá $\mathrm{Ka}$ dishá de Madrid y la Comunidad Judía de Madrid. $\mathrm{Al}$ acto acudieron todas las autoridades locales y nacionales implicadas en la gestión de la necrópolis. Lo ocurrido con este cementerio constituye un verdadero toque de atención para las administraciones competentes de cara a la preservación de este tipo de patrimonio en ciudades como Toledo.

Para evitar que se vuelvan a producir casos como el del Quixote Crea o IES Azarquiel es necesario la creación de un Plan Director que contemple la gestión de estos restos. Este plan debe recoger tanto los límites actualizados de los cementerios del exterior de la ciudad como las zonas potencialmente sensibles, con una metodología unificada y un equipo de especialistas que lo coordine. La mayor parte de la ampliación norte de la ciudad se encuentra sobre las necrópolis romana, visigoda, musulmana, judía y cristiana. Muchos de los parques como el Circo Romano y las Tres Culturas, son pequeñas islas en las que se conserva intacto este legado, las actuaciones urbanísticas deben regirse por un mapa de riesgo que minimice la afección a este peculiar patrimonio.

En ambos casos llama la atención lo extremo de sus planteamientos. De un lado, la total oposición a su manipulación por la comunidad rabínica internacional, de otro la total desidia y falta de interés en su preservación, por parte de las administraciones responsables de las obras del Quixote. En el caso español, la reflexión se debe extender al conjunto de la sociedad que es, en definitiva, la que habilita a los gestores de nuestras administraciones públicas. Aunque pueda parecer extraño en estos tiempos, existe un término medio, un equilibrio en el que los intereses de todas las partes pueden verse representados. 


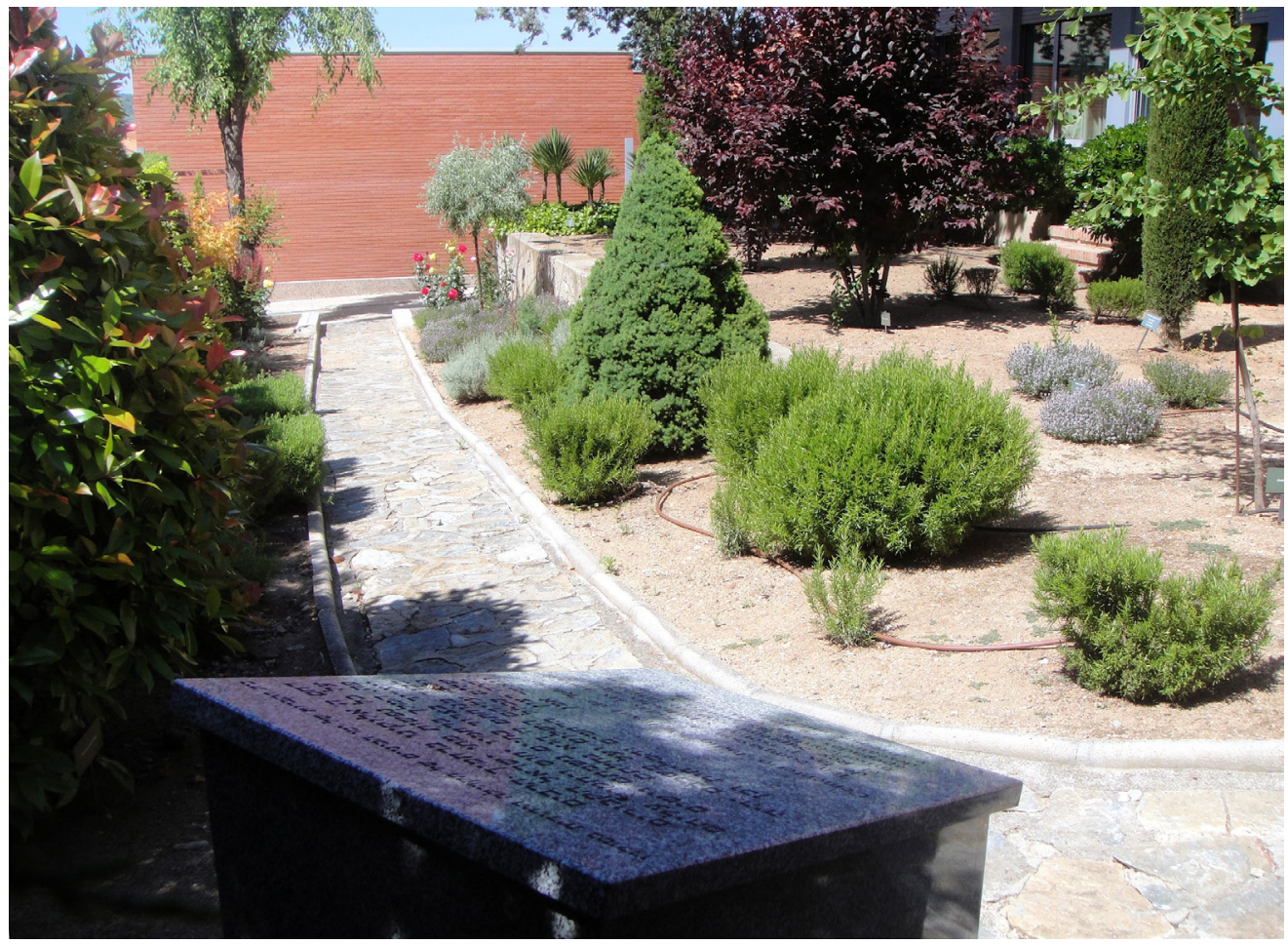

Figura 6.- Jardín y placa conmemorativa del cementerio judío de Toledo.

\section{Consideraciones finales}

En la sociedad occidental muchas de las reivindicaciones tratadas en este artículo son vistas por el común de la población como algo folclórico, alejado a sus quehaceres y realidad cotidiana. Cambiar esta tendencia resulta casi imposible en un mundo en el que la globalización marca los ritmos de la información, en una sociedad que, en los últimos años, tiende a reducir sus inquietudes intelectuales, sociales y culturales a 140 caracteres. En occidente, la mezcla de lo real y lo imaginario, de hechos y normas, no deja de constituir un formidable campo de energía que atrae hacia sí y rechaza al mismo tiempo a las demás sociedades (Godelier 2000: 218).

Hemos visto como el tratamiento de los restos humanos varía en relación al contexto social y las circunstancias en las que se produce. Este tratamiento es argumento de foros de debate como el celebrado en Junio de 2006 sobre la propiedad de la herencia cultural y la gestión de restos humanos organizado por el Museo Branly (Latour 2006), o sobre intervenciones arqueológicas en cementerios históricos celebrada en el Museo de Historia de Barcelona los días 15 y 16 de enero de 2009 (Colomer 2012). En este sentido, la arqueología se está convirtiendo en un nuevo campo de batalla entre el laicismo y la religión, entre la tradición y lo meramente científico, entre lo sentimental y lo real (Colomer 2012).

Frente a otras consideraciones, la reivindicación religiosa es la que presenta un mayor vacío en cuanto a la gestión de sus restos por la subjetividad de sus planteamientos. Dicha reivindicación choca con el laicismo imperante en occidente. Este laicismo tiene su origen en la Ilustración, que consagra la idea de que la sociedad del siglo XVIII era más civilizada y superior a las otras del pasado o del presente porque estaba regida por individuos que no se dejaban llevar por emociones en su relación con el mundo. La separación que se produce entonces entre la sociedad y la iglesia, es la que hoy en día nos diferencia de otras culturas, cuya base aún se rige en torno a leyes religiosas (Colomer 2010: 84). Esta desacralización de la vida pública occidental ha permitido emplear símbolos cristianos como mero reclamo laico, aprovechando la controversia que estos temas aún produce en una parte de la población. La desacralización de iglesias y monasterios ha hecho que muchos de los lugares que antaño se destinaban al culto, se vean reconvertidos en bares, hoteles o salas de exposiciones. Esta utilización laica de edificios religiosos en desuso, aunque muy cuestionada, choca frontalmente con muchas minorías étnicas que aún 
mantienen un respeto escrupulosos a sus símbolos y manifestaciones culturales.

Alguna de estas comunidades religiosas y étnicas con presencia en Occidente, han comenzado a reivindicar su pasado. En España, la añoranza de al Andalus por parte de sectores integristas islámicos o la lucha por preservar los cementerios judíos de Europa, son reflejo de esta tendencia. En este nuevo escenario, asistimos a la creciente demanda de uso mezquitas y sinagogas para restaurar su culto original (Fig. 7). La falta de una política clara de actuación en materia de patrimonio representa un caldo de cultivo para que, en un futuro, proliferen este tipo de conflictos. Para evitar esto, se debe partir de la premisa de que las poblaciones cambian, las costumbres evolucionan y la rotundidad con que se afirma que se habla en nombre de los muertos tiene que matizarse con la aceptación por parte de todas las partes afectadas de nuestro legado humano común independientemente de la diversidad cultural (Silberman 2012: 241).

En este artículo hemos analizado algunos ejemplos en los que se abarca desde diferentes ópticas algunos problemas derivados de la gestión de los restos humanos de las comunidades que los reivindican. El objetivo ideal debiera ser la recuperación para el conjunto de la sociedad de nuestro pasado, independientemente de sus condicionantes étnicos, políticos, sociales y religiosos. En palabras de Polonovski (2012: 302), toda comunidad diferente en un país democrático puede vivir conforme a sus creencias y rituales, puede crear patrimonio para el presente y para el futuro, pero el pasado nos pertenece a todos. La territorialidad implica toda una serie de factores geográficos, ecológicos, económicos, políticos, religiosos, sociológicos, y étnicoculturales. La emigración ocasiona la pérdida de este sentimiento territorial que, en muchos casos, se mantiene de forma ideal en los países receptores de la misma. En este sentido, hemos visto como muchas de las reivindicaciones que se producen en occidente promovidas por grupos judíos responde a un intento de legitimización provocado por la falta de un lugar físico de referencia.

De todos los casos tratados, la puesta en valor del cementerio del Commons en Manhattan sirve de ejemplo de cómo el patrimonio histórico enriquece a la sociedad que lo sabe gestionar, mientras que el de la gestión de la memoria histórica en España, aunque sigue la misma línea, requiere profundizar en sus planteamientos y objetivos. Por desgracia, en el resto de los casos ha quedado de manifiesto el uso político de este patrimonio, en donde se deja en un segundo plano las reivindicaciones legítimas de los afectados. Los de Mamilla y Bet Shearin representan, en cambio, la instrumentalización a

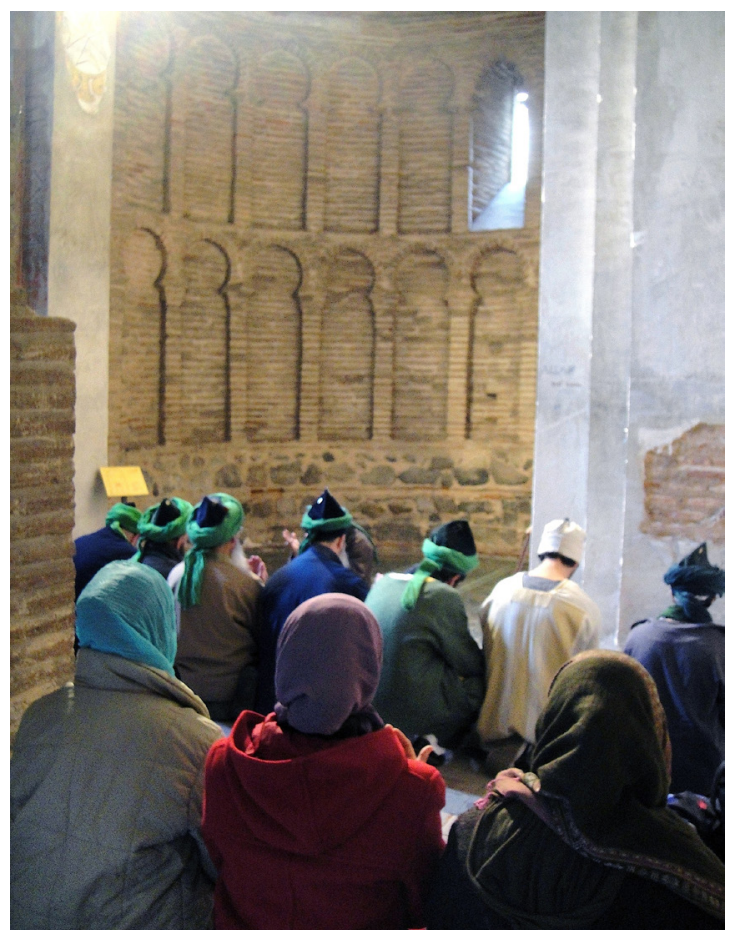

Figura 7.- Momento de oración de la comunidad sufí Naqshbandi en la antigua mezquita de Bab al Mardum, actual iglesia del Cristo de la Luz de Toledo (27 de noviembre de 2012).

la que pueden someterse los restos humanos. No debemos olvidarnos que los verdaderos motores de la noticia son los grupos minoritarios de ambas facciones. En este sentido, la mayoría musulmana y judía considera que tanto la ultra-ortodoxia judía como los movimientos islámicos integristas representan el verdadero impedimento para que Israel pueda algún día vivir en paz. Ambas facciones se sirven de los muertos, sean reales o imaginarios, como excusa para sus reivindicaciones.

Las manifestaciones frente a los consulados de España en el extranjero por parte de grupos ultra ortodoxos para protestar por el saqueo de sus tumbas en Toledo ilustra la actitud de algunos sectores judíos para preservar los restos de sus antepasados. La comunidad musulmana internacional está empezando a sensibilizarse con el trato que se le da a sus cementerios históricos en occidente. La cristiana, más allá de la desidia secular que ha caracterizado la preservación de sus enterramientos, comienza tímidamente a mostrar su preocupación sobre el destino de los restos humanos, una vez finalizadas las obras de rehabilitación y excavación arqueológica en sus iglesias. Con el tiempo no nos debe extrañar que este tipo de reivindicaciones se multiplique por Europa. 
El caso de Toledo ilustra el problema emergente de la gestión de los cementerios históricos en occidente. La excavación del IES Azarquiel y la destrucción de parte de la necrópolis medieval en el Quixote Crea, ha evidenciado la falta de un protocolo de actuación para este tipo de yacimientos. Pese a la puesta en funcionamiento de la nueva normativa en materia de patrimonio a nivel regional (Ley de Patrimonio de Castilla La Mancha, 4/13), se echa en falta la redacción de un plan director que regule las intervenciones arqueológicas en zonas en las que se presuponga la existencia de restos humanos. Como hemos visto, este plan director debe recoger una metodología de excavación de tumbas común para todas las intervenciones, un mapa de riesgo en el que se indique la localización de los principales cementerios históricos toledanos y sus áreas de contacto, y un proyecto de divulgación y puesta en valor de los diferentes espacios funerarios extramuros de la ciudad. En este sentido, Toledo no sólo debe ser conocido mundialmente por sus monumentos, murallas o puertas, sino por una oferta cultural que aglutine la totalidad de su historia. Los lugares de enterramiento, aún siendo lo menos conocido, son pieza clave para comprender nuestro pasado.

\section{Notas}

1. Quiero agradecer los comentarios y aportaciones hechos al borrador de este artículo tanto a los evaluadores ciegos de la revista Complutum, como a Santiago Palomero, Sandra Azcárraga, Jean Passini e Ignacio Montero, no obstante, cualquier error de apreciación o contenido es exclusivamente mío.

\section{REFERENCIAS BIBLIOGRÁFICAS}

Aranda, C.M.; Del PaPa, M.C. (2009): Avance de las prácticas de conservación y manejo de restos humanos en Argentina. Revista Argentina de Antropología Biológica, 11(1): 89-93

BAfFi, E.I.; Berón, M.A. (2000): Propuesta para la integración del conocimiento de los sitios arqueológicos con restos óseos humanos. El sitio Chenque I, Provincia de Pampa. Relaciones de la Sociedad Argentina de Antropología, XXV: 145-158

Barrio Aldea, C. Ruiz Taboada, A.; Sánchez Peláez, E.; Rodríguez Untoria. S. (2011): Destrucción parcial de la necrópolis medieval de Toledo. Restauro, 10: 28-33.

BlaKey, M.L. (1998): The New York African burial Ground Project: An examination of slaves lives, a construction of ancestral ties. Transforming Anthropology, Volume 7(1): 53-58

Bruning, S.B. (2006): Complex legal Legacies: The Native American Graves Protection and Repatriation Act, scientific study and Kennewick man. American Antiquity, 71(3): 501-521

Colomer, L. (2010): Approaching Montjuïc as part of the historic Legacy of Barcelona. Museum International, 245-246. Vol. 62, 1-2: 81-85

Colomer, L. (2012): La intervención arqueológica en las necrópolis históricas. Los cementerios judios. Museo de Historia de Barcelona.

Cosmai, N.P.; Folguera, G.; Outomuro, D. (2013): Restitución, repatriación y normativa ética y legal en el manejo de restos humanos aborígenes en Argentina. Acta Bioethica, 19(1): 19-27

EnDERE, M.L. (2000): Patrimonios en disputa: Acervos nacionales, investigación arqueológica y reclamos étnicos sobre restos humanos. Trabajos de Prehistoria, 57. 1: 5-17

FERRANDIZ, F. (2006): The return of civil war ghosts. The ethnography of exhumations in contemporary Spain. Anthropology Today, 22(3): 7-12

FERRANDIZ, F. (2009): Exhumaciones y relatos de la derrota en la España actual. Jerónimo Zurita, 84: 135-162

Godelier, M. (2000): Cuerpo, parentesco y poder. Abya Yala, Ecuador.

Hodder, I. (2003): Archaeology Beyond Dialogue. Foundations of Archaeological Inquiry. University of Utah Press, Salt Lake City.

Latour, B. (2006): Le Dialogues des Cultures. Actes des rencontres inaugurales du musée du quai Branly (21 juin 2006). Coédition musée du quai Branly/Actes Sud.

Polonovsky, M. (2012): Los cementerios judíos y la arqueología: nuevos retos científicos y jurídicos. La intervención arqueológica en las necrópolis históricas. Los cementerios judios. (L. Colomer ed.) Museo de Historia de Barcelona: 295-302

Renshaw, L. (2011): Exhuming loss. Memory, materiality, and mass graves of the Spanish civil war. California, Left Coast Press.

Rodríguez LóPez, J.A. (2009): Ley federal NAGPRA, patrimonio arqueológico e identidad étnica en Puerto Rico. Boletín de Antropología Americana, 1: 59-98 
Ruiz Taboada, A. (2011): La necropole juive de Tòlede: Type, construction et distribution des tombes. L'Archéologie du judaïsme (P. Salmona y L. Sigal ed.) Inrap, Paris: 289-300

Ruiz Taboada, A. (2012): Arquitectura residencial y religiosa: Toledo (s. X-XVIII). La Ergástula, Madrid.

Ruiz Tabonda, A. (2013): La vida futura es para los devotos. La muerte en el Toledo medieval. La Ergástula, Madrid.

Salmona, P.; Sigal, L. (2011): L'Archéologie du judaïsme. Inrap, Paris.

Silberman, N. (2012): ¿Quién tiene que encargarse de los muertos? El método científico, los derechos humanos, la ética del patrimonio y las creencias de la comunidad. La intervención arqueológica en las necrópolis históricas. Los cementerios judíos. (L. Colomer ed.) Museo de Historia de Barcelona: 233-241

Silvan, R. (2012): Continuidad histórica y la problemática de excavaciones en necrópolis judías. La realidad de Israel. (L. Colomer ed.) La intervención arqueológica en las necrópolis históricas. Los cementerios judios. Barcelona: 25-32

Stultz, L. (2012): The Noah Complex and Archaeology in the Holy Land: The Case of the Mamilla Cemetery and the Museum of Tolerance and Human Dignity. Heritage and Society, 2: 221-248

Tomas, B.W. (2002): Struggling with the past: Some views of African American identity. International Journal of Historical Archaeology, 6(2): 143-151

Walsh-Haney, H.; Lieberman, L. (2005): Ethical concerns in Forensic Anthropology. Biological Anthropology and Ethics. From repatriation to genetic identity. (T. Turner ed.) Nueva York: 121-131. 